Article

\title{
Hydraulic Responses and Flow Regulation in Multi-Demand Water Transfer Systems
}

\author{
Xiaolian Liu ${ }^{1}$, Yu Tian ${ }^{2, *}$, Xiaohui Lei ${ }^{2}$, Honggang Fan ${ }^{3}$ and Hao Wang ${ }^{1,2}$ \\ 1 College of Water Resource and Hydropower, Sichuan University, Chengdu 610065, China \\ 2 State Key Laboratory of Simulation and Regulation of Water Cycle in River Basin, \\ China Institute of Water Resources and Hydropower Research, Beijing 100038, China \\ 3 State Key Laboratory of Hydroscience and Engineering, \\ Department of Energy and Power Engineering, Tsinghua University, Beijing 100084, China \\ * Correspondence: iwhr1985@163.com
}

Received: 2 October 2019; Accepted: 12 November 2019; Published: 15 November 2019

check for updates

\begin{abstract}
It is of great significance for the practical operation scheduling to comprehensively analyze the influencing factors of the long-term steady-state operation state of different water demand scenarios and the coupled operation of hydraulic facilities when switching demand scenario as the demand changes. In the study, a case study is performed in the Daxing Branch project, the numerical model of which considered pipelines, pumps, valves, air valves, and regulating tanks is established using Method of Characteristics. The hydraulic responses and corresponding flow regulation of different demand scenarios and between changing demand scenarios are analyzed. The results show that steady-state working conditions can have important impacts on the transient process. Energy consumption and the amount of water transfer, as well as water hammer pressure and the allowable reaction time during the transient process should be taken into account in the selection of long-term steady-state working conditions of different demand scenarios. The sequence and maximum allowable time interval of the coupled operation of pumps and valves should be considered when switching demand scenario. Finally, the optimal steady-state working conditions of different demand scenarios, the coupled operation sequence of pumps and valves, the maximum allowable time interval of the Daxing Branch project are proposed, which can provide some insights into the safe operation of the project and other similar complex water transfer projects.
\end{abstract}

Keywords: multi-demand water transfer system; the method of characteristics; the response of water level; flow and pressure; steady-state operation state; water hammer; coupled operation of pumps and valves

\section{Introduction}

A number of water-transfer projects have been constructed in China to allow continued development in arid and semi-arid regions that would otherwise have been constrained by natural limits. A water transfer project often serves multiple purposes and thus involves various structures and devices, making it challenging for reasonable selection of working conditions and flow regulation. Hydraulic transient is an intermediate flow condition where the flow velocity and pressure change rapidly with time due to, for example, opening and closing of sluices and pumps, mechanical failure of a device, and changes in water demand [1]. A pressure wave of $1000 \mathrm{~m} / \mathrm{s}$ or higher can be generated in a transient event and then propagated along the steel pipeline, often causing loud noises, severe vibration, and damage [2], such as pipeline rupture, collapse, water leakage, cavitation, and erosion [3,4]. Clearly, it should be taken into account in the design and operation of a water transfer project. Many numerical approaches have been developed to simulate transient flow in 
pipelines, such as the method of characteristics (MOC) [5-7], wave characteristics method (WCM) [8], finite volume method (FVM) [9], finite element method (FEM) $[10,11]$ and finite difference method (FDM) [12]. Among these methods, MOC is the most widely used because of its feasibility, simplicity, numerical efficiency, and superior performance over many other methods for complex systems [13].

Tian et al. [14] used MOC to analyze check valve-induced water hammer behaviors for a parallel pumps feedwater system during an alternate startup of these pumps. Sibetheros et al. [15] found that the overall accuracy of MOC with spline polynomials for interpolations was significantly improved compared to that with linear interpolations or to second-order explicit finite difference techniques in numerical analysis of water hammers caused by sudden valve closure in a frictionless horizontal pipe. Afshar et al. [1] proposed an implicit method of characteristics (IMOC) allowing for an arbitrary combination of devices in a pipeline system. Wan et al. [16] simulated hydraulic transient of centrifugal pump failure and start-up using MOC. Vakil et al. [17] developed a computational model using MOC to investigate the effects of valve-closing laws on the maximum head rise at the end of the pressure shaft and other components. Kim et al. [18] simulated hydraulic transient in a pump rising pipeline system using MOC and investigated the selection of air chamber size and the effect of the inner diameter of the orifice to minimize water hammer.

These achievements are useful to reasonably select the hydraulic facilities and the layout of water transfer system at the design stage in order to reduce the water hammer. However, a multi-demand water transfer system needs to meet a variety of demand scenarios. Additionally, under the same demand scenario, there are many working conditions for hydraulic facilities. Therefore, it is necessary to study the main influencing factors for the selection of long-term steady-state working conditions. Moreover, pump and valve operations are likely to be coupled in the water transfer project with multiple water sources and structures [19], which may cause a severe surge in pressure and flow, as well as overpressure, overflow, and reverse flow in the system. Therefore, the coupled operation of hydraulic facilities when switching demand scenario as the demand changes are also necessary to be analyzed.

In the study, a numerical simulation model of the Daxing Branch project, an important project of the South-to-North Water Transfer Project, China, was established using MOC to study the hydraulic characteristics of the steady-state working condition and characterize the transient interference between pumps and valves. The main influencing factors for the selection of long-term steady-state working conditions, and the coupled operation of hydraulic facilities when switching demand scenario as the demand changes are analyzed. Finally, the optimal steady-state working conditions of different demand scenarios, the coupled operation sequence of pumps and valves, the maximum allowable time interval of the Daxing Branch project are proposed, which can provide some insights into the safe operation of the project and other similar complex water transfer projects.

\section{Materials and Methods}

\subsection{Study Area and Test Scenarios}

The Daxing Branch project is intended to connect the South Branch project in Beijing with the Langzhuo Branch project in Hebei province for water supply from Hebei province to Beijing or vice versa, or from Hebei province or Beijing to the new airport. The length of the pipe between Beijing and Hebei province is about $46 \mathrm{~km}$, with a diameter of $2.4 \mathrm{~m}$, and a design flow rate of $6.1 \mathrm{~m}^{3} / \mathrm{s}$; while that to the new airport is about $14 \mathrm{~km}$, with two diameters of $1.8 \mathrm{~m}$ and a design flow rate of $4.9 \mathrm{~m}^{3} / \mathrm{s}$. They are all ductile iron pipes. The thickness of the pipe is $0.025 \mathrm{~m}$ and the coefficient of roughness is 0.012. As the Daxing branch line to the new airport water plant pipeline is still under construction, the simulation length of the new airport line is $1.84 \mathrm{~km}$. The water demand of the new airport is estimated to be $2.1 \mathrm{~m}^{3} / \mathrm{s}$ in the near future and $4.9 \mathrm{~m}^{3} / \mathrm{s}$ in the long term, respectively.

The Daxing Branch project includes pump station, regulating tank, surge chamber, air valves, and valves. The pump station consists of three pumps with a design head of $40 \mathrm{~m}$, a design flow of 
$2.0 \mathrm{~m}^{3} / \mathrm{s}$, a design speed of $590 \mathrm{r} / \mathrm{min}$, and a specific speed of 135 . The inlet and outlet pipes of the pump are $1 \mathrm{~m}$ in diameter. Regulating tank is used when water sources and working conditions are changed or as forebay of the pumping station, and its effective volume is about $30,000 \mathrm{~m}^{3}$, with a maximum operating water level of $34.0 \mathrm{~m}$, a minimum operating water level of $29.2 \mathrm{~m}$. The overflow water level of the surge chamber is $58.5 \mathrm{~m}$, the sectional area is $13.85 \mathrm{~m}^{2}$. There are 91 air valves installed along the pipeline. The inlet and outlet diameter of the air valve is $300 \mathrm{~mm}$, and the diameter of the micro hole is $24.5 \mathrm{~mm}$. The piping system is schematically shown in Figure 1. The longitudinal profile of the pipeline and the location of the air valve, pump, valve, and surge chamber are shown in Figure 2. The valves are control valves. Additionally, the relationship between valve opening and valve flow resistance coefficient is shown in Table 1.

The design water level of the connection between the South Branch project and the Daxing Branch project is $51.739 \mathrm{~m}$. The design water level of the connection between the Langzhuo Branch and the Daxing Branch project is $45.73 \mathrm{~m}$ for water supply from Hebei province to Beijing.

In the study, three scenarios are considered for water supply from the Langzhuo Branch to the South Branch (OS1) and from the Langzhuo Branch to the South Branch and the new airport with a flow rate of $2.1(\mathrm{OS} 2)$ and $4.9 \mathrm{~m}^{3} / \mathrm{s}(\mathrm{OS} 3)$, respectively.

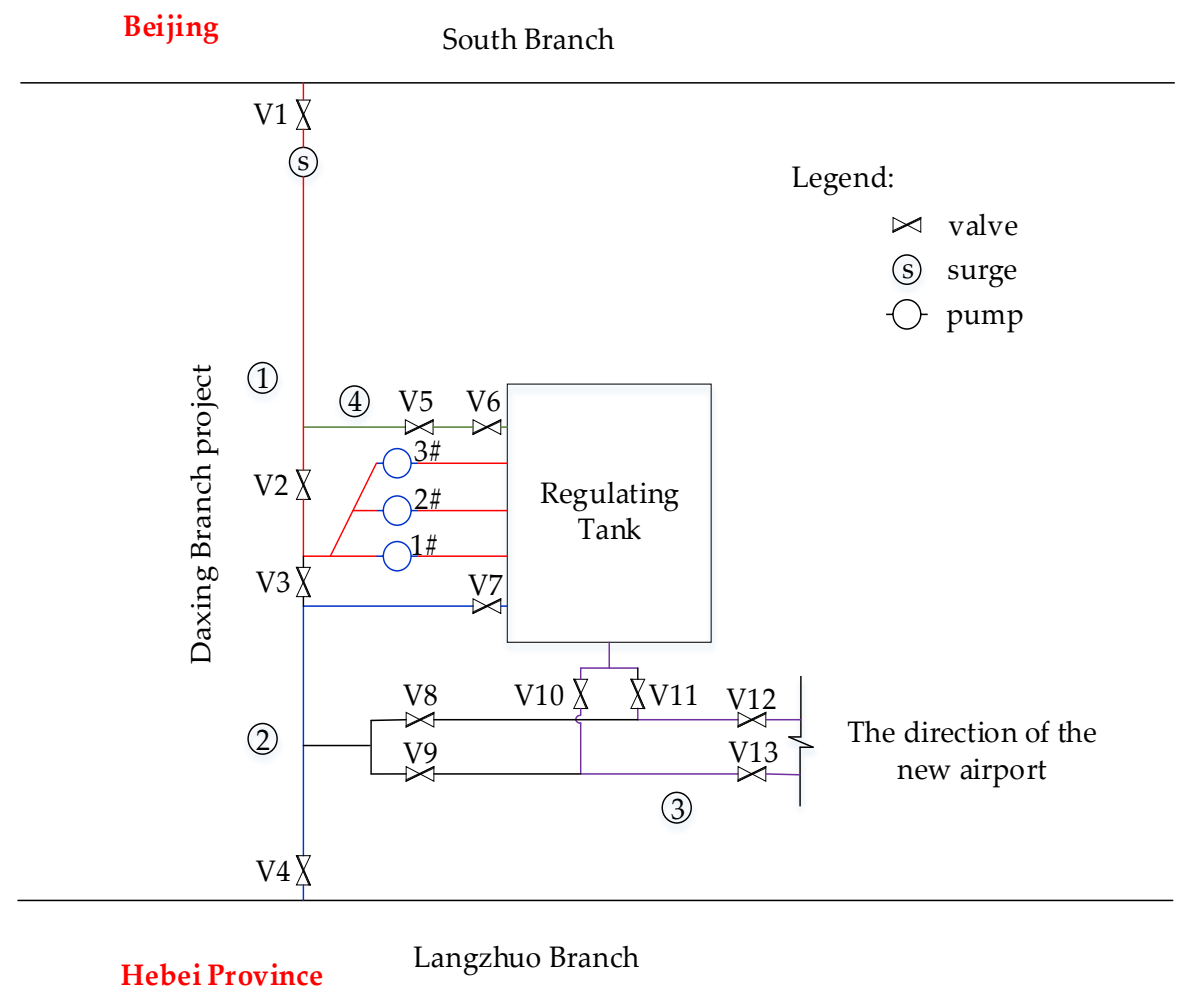

Figure 1. A schematic of the piping system of the Daxing Branch project.

Table 1. Relationship between valve opening and valve flow resistance coefficient.

\begin{tabular}{cccc}
\hline The Valve Opening & $\begin{array}{c}\text { The Valve Flow } \\
\text { Resistance Coefficient }\end{array}$ & The Valve Opening & $\begin{array}{c}\text { The Valve Flow } \\
\text { Resistance Coefficient }\end{array}$ \\
\hline $0 \%$ & $1 \times 10^{13}$ & $70 \%$ & 29 \\
$10 \%$ & $1 \times 10^{7}$ & $75 \%$ & 21 \\
$20 \%$ & $9 \times 10^{4}$ & $80 \%$ & 15 \\
$30 \%$ & $4 \times 10^{3}$ & $85 \%$ & 11.5 \\
$40 \%$ & 650 & $90 \%$ & 9.3 \\
$50 \%$ & 170 & $95 \%$ & 8.4 \\
$60 \%$ & 65 & $100 \%$ & 8.1 \\
\hline
\end{tabular}



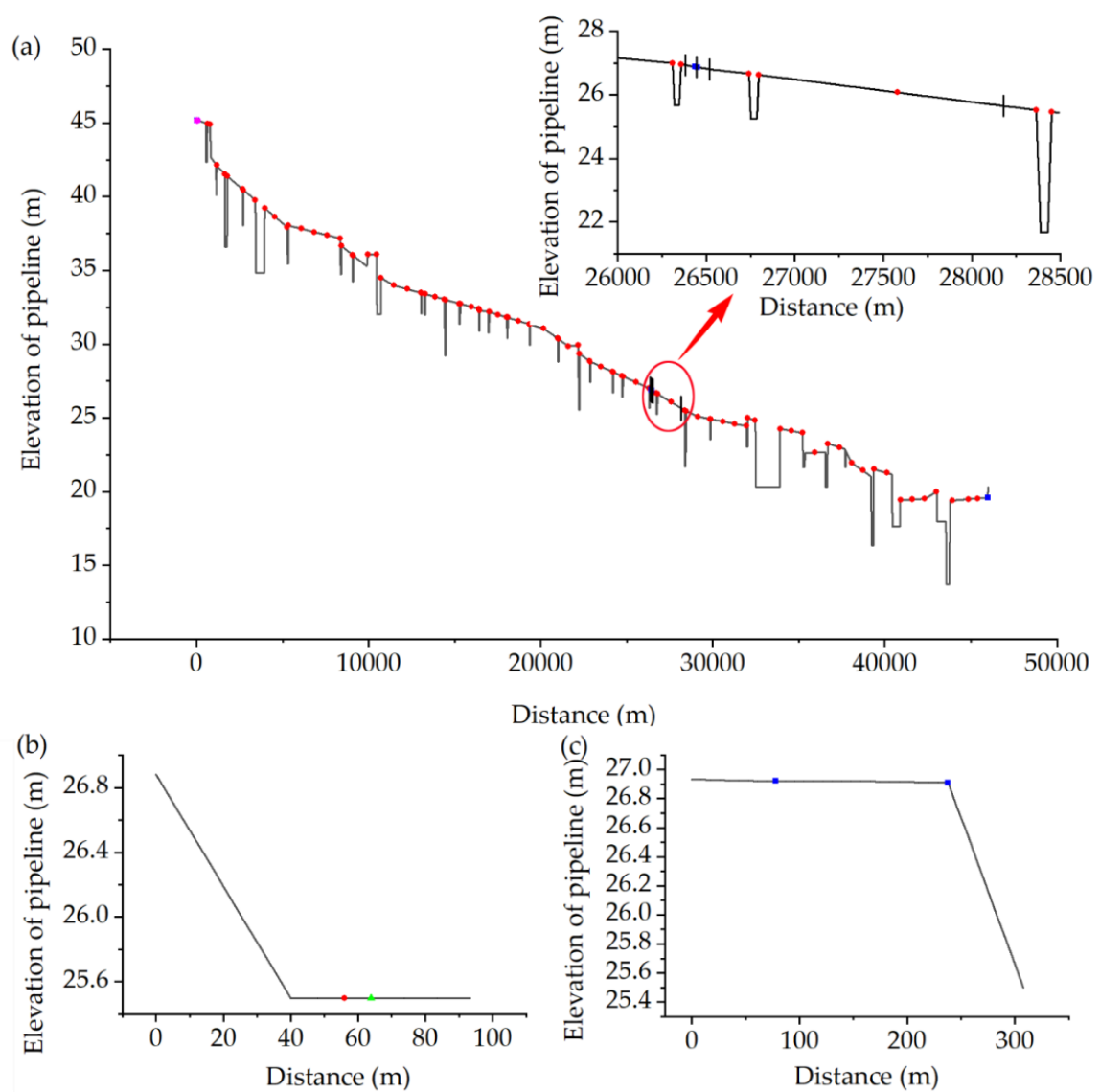

Distance $(\mathrm{m})$
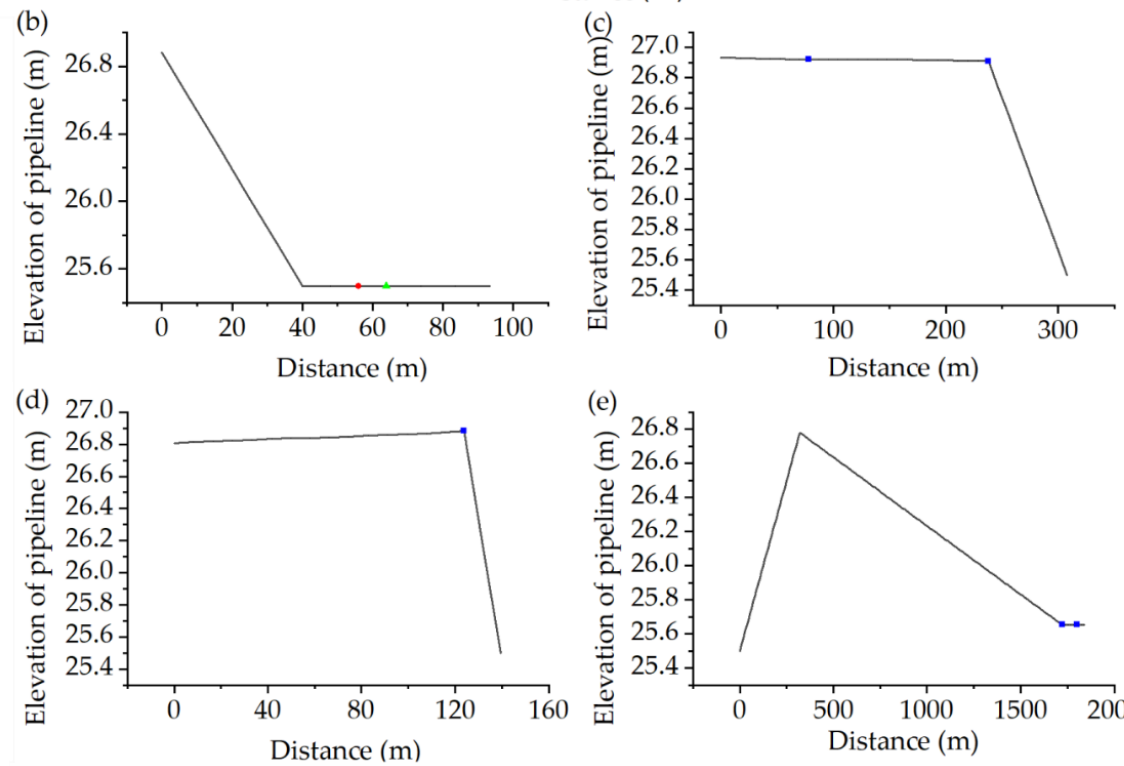

(e)
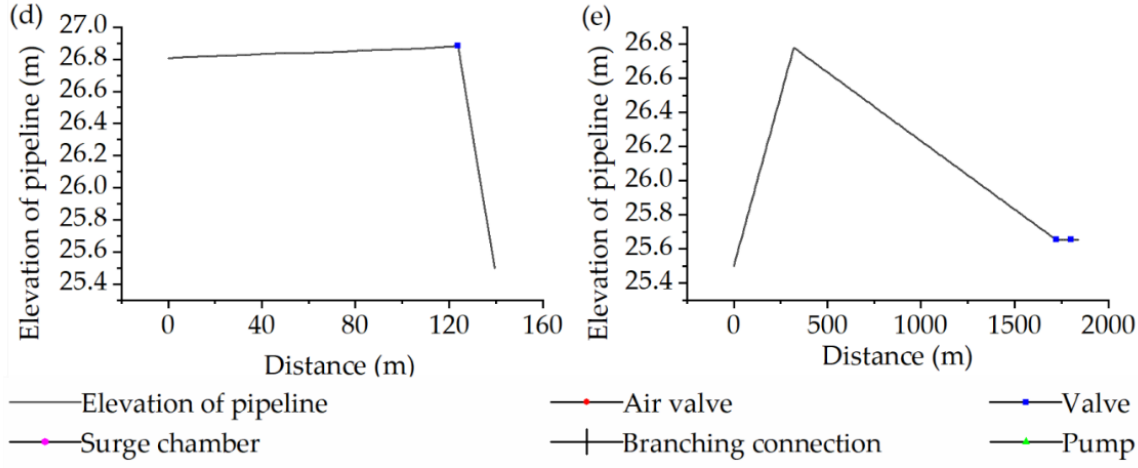

Figure 2. A longitudinal profile of (a) the pipeline of Beijing and Hebei province; (b) the branch to regulating tank of the pipeline (1); (c) the pipeline (4); (d) the branch to regulating tank of the pipeline (2); (e) the pipeline (3) and the location of the air valves, pumps, valves, and surge chamber.

\subsection{Numerical Simulation of the Study Area}

A water transfer project often serves multiple purposes and thus involves various structures and devices, such as valves, air valves and pumps, which are often treated as boundary conditions in MOC for governing equations of transient flow in pipes.

\subsubsection{Method}

The momentum and continuity equations are the governing equations of the one-dimensional unsteady fluid flow in pipelines. The MOC approach transforms the water hammer partial differential equations into ordinary differential equations along the characteristic lines, which are called the compatibility equations:

$$
C^{+}: \frac{d x}{d t}=a, \quad H_{i}^{j+1}=C_{p}-B Q_{i}^{j+1}
$$




$$
C^{-}: \frac{d x}{d t}=-a, \quad H_{i}^{j+1}=C_{M}+B Q_{i}^{j+1}
$$

where $C_{p}=H_{i-1}^{j}+(B+C) Q_{i-1}^{j}-R Q_{i-1}^{j}\left|Q_{i-1}^{j}\right|, C_{M}=H_{i+1}^{j}-(B-C) Q_{i+1}^{j}+R Q_{i+1}^{j}\left|Q_{i+1}^{j}\right|, B=\frac{a}{g A}$, $C=\frac{\Delta t}{A} \sin \alpha, R=\frac{f \Delta x}{2 g D A^{2}}, f=\frac{8 g n^{2}}{(D / 4)^{1 / 3}}, i$ is the node number of the pipe segment and $j$ is the time layer number; $\Delta x$ is the length of the pipe segment between two adjacent nodes; $\Delta t$ is the duration between two adjacent time layers; $\alpha$ is the inclination angle of the pipe centerline; $a$ is the wave celerity; $g$ is the acceleration of gravity; $D, A$, and $n$ are the diameter, area, and the coefficient of roughness of the pipe, respectively.

\subsubsection{Boundary Conditions}

\section{Valve}

As a valve is installed between two pipes, the orifice Equation (3) should be solved in conjunction with the compatibility equations, and then the flow rate can be calculated using Equation (4).

$$
\begin{gathered}
Q_{p}=\tau Q_{0} \sqrt{\Delta H / \Delta H_{0}} \\
Q_{p}=-C_{v}\left(B_{1}+B_{2}\right)+\sqrt{C_{v}^{2}\left(B_{1}+B_{2}\right)^{2}+2 C_{v}\left(C_{P 1}-C_{M 2}\right)}
\end{gathered}
$$

where $C_{v}=Q_{0}^{2} \tau^{2} / 2 \Delta H_{0}, \tau$ is the relative valve opening; $Q_{0}$ and $\Delta H_{0}$ are the steady-state flow rate and head difference, respectively; $Q_{p}$ and $\Delta H$ are the transient flow rate and head difference; $B_{1}$ and $C_{p 1}$ are the parameters of the pipe upstream of the valve, $B_{2}$ and $C_{p 2}$ are the parameters of the pipe downstream of the valve.

It is also important to take into account the possibility of flow reversal that occurs when $C_{P 1}-C_{M 2}<0$. In this case, the orifice equation can be rewritten as Equation (5), and the flow rate can be calculated using Equation (6):

$$
\begin{gathered}
Q_{p}=-\tau Q_{0} \sqrt{\Delta H / \Delta H_{0}} \\
Q_{p}=C_{v}\left(B_{1}+B_{2}\right)-\sqrt{C_{v}^{2}\left(B_{1}+B_{2}\right)^{2}-2 C_{v}\left(C_{P 1}-C_{M 2}\right)}
\end{gathered}
$$

The valve at the end of the pipe can be considered as a special case.

According to the literature [20], the relative valve opening $\tau$ and valve flow resistance coefficient

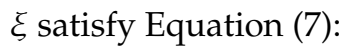

$$
\tau=\left(\xi_{0} / \xi\right)^{0.5}
$$

$\xi_{0}$ is the valve flow resistance coefficient when the valve is fully open.

Then, the relationship between the valve opening and the relative valve opening used for calculation can be obtained through the relationship between the valve opening and valve flow resistance coefficient, as shown in Table 2.

Table 2. Relationship between the valve opening and the relative valve opening.

\begin{tabular}{cccc}
\hline The Valve Opening & $\begin{array}{c}\text { The Relative Valve } \\
\text { Opening }\end{array}$ & The Valve Opening & $\begin{array}{c}\text { The Relative Valve } \\
\text { Opening }\end{array}$ \\
\hline $0 \%$ & 0.0000 & $70 \%$ & 0.5285 \\
$10 \%$ & 0.0009 & $75 \%$ & 0.6211 \\
$20 \%$ & 0.0095 & $80 \%$ & 0.7348 \\
$30 \%$ & 0.0450 & $85 \%$ & 0.8393 \\
$40 \%$ & 0.1116 & $90 \%$ & 0.9333 \\
$50 \%$ & 0.2183 & $95 \%$ & 0.9820 \\
$60 \%$ & 0.3530 & $100 \%$ & 1.0000 \\
\hline
\end{tabular}




\section{Pump}

The boundary condition of pumps can be described by the net torque equation and the head balance equation. The head balance Equation (8) is solved in conjunction with the compatibility and continuity equations, and then it becomes Equation (9).

$$
\begin{gathered}
H_{P S}+t d H_{p}=H_{P U} \\
t d H_{p}=C_{M}-C_{P}+\left(B_{S}+B_{U}\right) Q_{P}
\end{gathered}
$$

where $H_{P S}$ and $H_{P U}$ are the pressure head of the last section on the inlet side and the first section on the outlet side, respectively; $t d H_{P}$ and $Q_{P}$ are the pump head and flow rate, respectively; $B_{S}$ and $C_{P}$ are the parameters of the pipe on the inlet side, and $B_{U}$ and $C_{M}$ are the parameters of the pipe on the outlet side. The pump head and flow rate can be calculated using the characteristic equations of the pump, which are usually defined graphically in terms of the four non-dimensional quantities:

$$
h=\frac{t d H_{p}}{t d H_{r}}, \beta=\frac{T_{P}}{T_{r}}, \alpha=\frac{n_{P}}{n_{r}}, v=\frac{Q_{P}}{Q_{r}}
$$

where $t d H_{r}, T_{r}, n_{r}$, and $Q_{r}$ are the pump head, net torque, rotational speed, and flow rate of the pump at rated conditions, respectively; and the subscript $P$ denotes the value in the current time. The characteristic curves are usually plotted in terms of the following, and which the pumps of the Daxing Branch project is shown Figure 3.

$$
x=\pi+\tan ^{-1}\left(\frac{v}{\alpha}\right), W H(x)=\frac{h}{\alpha^{2}+v^{2}}, W B(x)=\frac{\beta}{\alpha^{2}+v^{2}}
$$

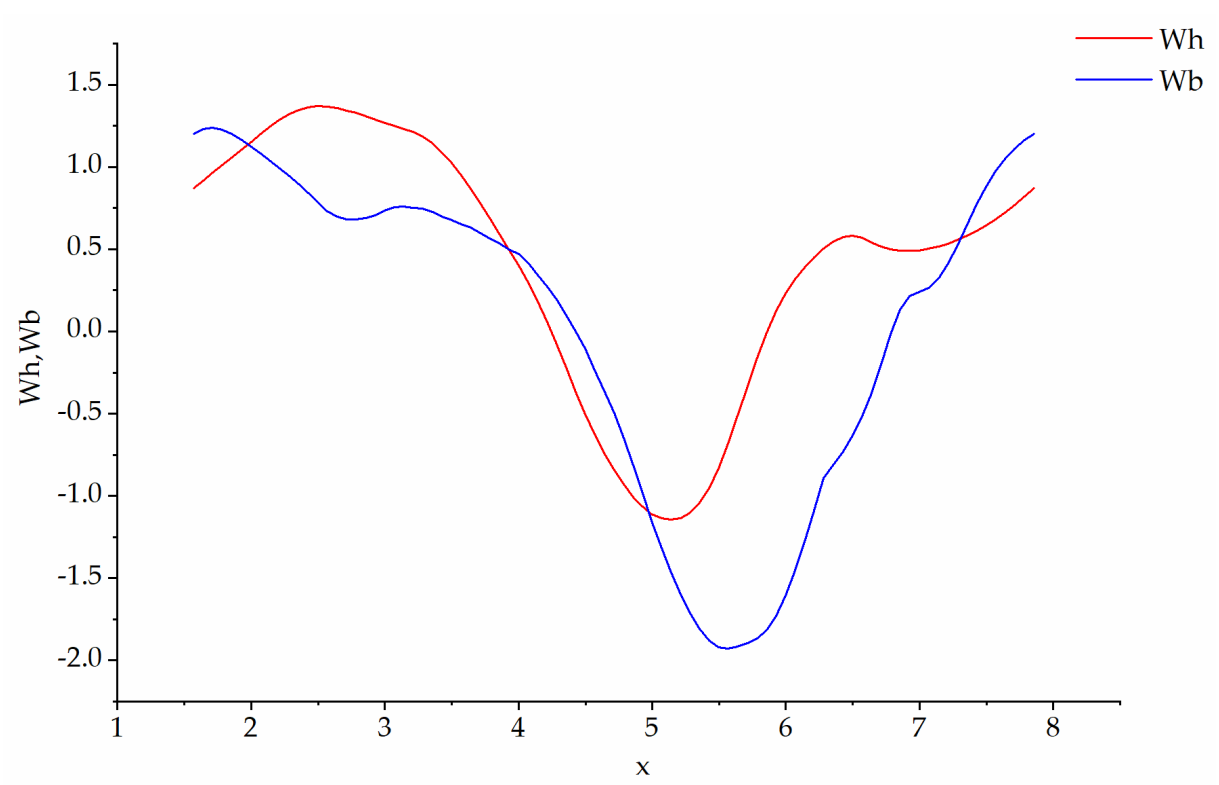

Figure 3. The characteristic curves of the pumps of the Daxing Branch project.

Moreover, a linear extrapolation is usually used to arrive at the following relations:

$$
W H(x)=A_{0}+A_{1} x, W B(x)=B_{0}+B_{1} x
$$

where $A_{0}, A_{1}, B_{0}$, and $B_{1}$ are the constants for the straight lines representing the head and torque characteristic curves, respectively. 
Substituting $t d H_{P}$ and $Q_{P}$ from Equations (10)-(12) into Equation (9) and yields the following equation:

$$
F_{1}=C_{P}-C_{M}-\left(B_{S}+B_{U}\right) Q_{r} v+t d H_{r}\left(\alpha^{2}+v^{2}\right)\left[A_{0}+A_{1}\left(\pi+\tan ^{-1} \frac{v}{\alpha}\right)\right]=0
$$

Similarly, the net torque Equation (14) can be transformed into Equation (15).

$$
\begin{gathered}
T_{P}=-I \frac{2 \pi}{60} \frac{d n_{p}}{d t} \\
F_{2}=\left(\alpha^{2}+v^{2}\right)\left[B_{0}+B_{1}\left(\pi+\tan ^{-1} \frac{v}{\alpha}\right)\right]+\beta_{0}+I \frac{n_{r}}{T_{r}} \frac{\pi}{15 \Delta t}\left(\alpha-\alpha_{0}\right)=0
\end{gathered}
$$

where $I$ is the combined polar moment of inertia of the pump, $\Delta t$ is the calculated time step, $\alpha_{0}$ and $\beta_{0}$ are the relative value of the rotational speed and net torque of the previous moment, respectively.

3. Surge Chambers and Regulating Tanks

The boundary conditions of surge chambers and regulating tanks can be calculated from Equations (16) and (17), respectively.

$$
\begin{gathered}
Q_{I}=Q_{S}+Q_{O}, A_{S} \frac{d H_{S}}{d t}=Q_{S} \\
\frac{H_{S}-Z}{g A_{S}} \frac{d Q_{S}}{d t}=H_{P}-H_{S}-\frac{f_{S}\left(H_{S}-Z\right)\left|Q_{S}\right| Q_{S}}{2 g D_{S} A_{S}^{2}}-\frac{\left|Q_{S}\right| Q_{S}}{g A_{S}^{2}}-\sigma \frac{\left|Q_{S}\right| Q_{S}}{2 g \omega^{2}}
\end{gathered}
$$

where $A_{S}$ and $D_{S}$ are the cross sectional area and the diameter of the surge chamber; $H_{S}$ is the water head in the surge chamber; $Z$ is the bottom elevation of the surge chamber; $H_{P}$ is the water head at the intersection of the center line of the surge chamber and the pipe; $f_{S}$ is the friction factor of the surge chamber; $\sigma$ and $\omega$ are the head loss coefficient and the cross sectional area of the impedance hole; $Q_{S}$ is the flow rate into the surge chamber; $Q_{I}$ and $Q_{O}$ are the flow rate on the inlet and outlet side, respectively.

Then, Equation (18) can be obtained.

$$
\left\{\begin{array}{l}
\frac{C_{P}}{B_{P}}+\frac{C_{M}}{B_{M}}-\left(\frac{1}{B_{P}}+\frac{1}{B_{M}}\right) H_{P}=Q_{S} \\
H_{S 0}+\frac{0.5 Q_{S 0} \Delta t}{A_{S}}+\frac{0.5 \Delta t}{A_{S}} Q_{S}=H_{S} \\
H_{P}-H_{S}=-\frac{2\left(H_{S 0}-Z\right) Q_{S 0}}{g A_{S} \Delta t}-H_{P 0}+H_{S 0}+\frac{2\left(H_{S 0}-Z\right)}{g A_{S} \Delta t}+\frac{1}{g}\left(\frac{\sigma}{\omega^{2}}+\frac{f_{S}\left(H_{S 0}-Z\right)}{D_{S} A_{S}^{2}}+\frac{2}{A_{S}^{2}}\left|Q_{S 0}\right|\right.
\end{array}\right.
$$

4. Air Valve

When the pressure inside the pipe where the air valve is installed is lower than the local atmospheric pressure, the air valve will be opened for the admittance of air into the pipe; otherwise the air inside the pipe would escape. On the basis of four assumptions [21,22], the mass flow rate of the air through the air valve $d m / d t$ is dependent on atmospheric pressures $\left(P_{0}\right.$ and $\left.P\right)$ and absolute temperatures $\left(T_{0}\right.$ and $T$ ) outside and inside the pipe, respectively:

$$
\begin{gathered}
\frac{d m}{d t}=C_{1} A_{1} \sqrt{7 P_{0} \rho_{0}\left[\left(\frac{P}{P_{0}}\right)^{1.4286}-\left(\frac{P}{P_{0}}\right)^{1.7143}\right]}, \quad P_{0}>P>0.528 P_{0} \\
\frac{d m}{d t}=C_{1} A_{1} \frac{0.686}{\sqrt{R T_{0}}} P_{0}, \quad P \leq 0.528 P_{0} \\
\frac{d m}{d t}=-C_{2} A_{2} \sqrt{\frac{7}{R T}\left[\left(\frac{P_{0}}{P}\right)^{1.4286}-\left(\frac{P_{0}}{P}\right)^{1.7143}\right]}, \quad \frac{P_{0}}{0.528}>P>P_{0}
\end{gathered}
$$




$$
\frac{d m}{d t}=-C_{2} A_{2} \frac{0.686}{\sqrt{R T}} P, \quad P>\frac{P_{0}}{0.528}
$$

where $C_{1}$ and $C_{2}$ are the discharge coefficients of inflow and outflow air valve, respectively; $A_{1}$ and $A_{2}$ are the areas of inflow and outflow air valve opening, respectively; $\rho_{0}$ is the mass density of atmospheric air, and $R$ is the gas constant.

The general gas equation can be solved in conjunction with compatibility equations and air mass flow rate equations, which becomes Equation (23) and can be solved by difference methods.

$$
\begin{aligned}
& P\left\{V_{0}+0.5 \Delta t\left[Q_{i}-Q_{p x i}-\left(\frac{C_{P}}{B_{P}}+\frac{C_{M}}{B_{M}}\right)+\left(\frac{1}{B_{P}}+\frac{1}{B_{M}}\right)\left(\frac{P}{\rho g}+Z-\bar{H}\right)\right]\right\} \\
& =\left[m_{0}+0.5 \Delta t\left((d m / d t)_{0}+(d m / d t)_{i}\right)\right] R T_{0}
\end{aligned}
$$

where $V_{0}$ is the initial volume of the cavity; $Q_{i}$ and $Q_{p x i}$ are the initial inflow into and outflow from the cavity; $m_{0}$ is the initial mass of air in the cavity; $(d m / d t)_{0}$ and $(d m / d t)_{i}$ are the initial and final rate of air mass flowing into and out of the cavity; $Z$ is the height of air valve that overtops the base level; and $\bar{H}$ is the local barometric head, respectively.

\section{5. $\quad$ Fixed Water Levels}

Assuming that the water level of upstream and downstream reservoirs is to be constant during the transition, and combined with the compatibility equations to arrive at the final boundary equations of fixed water level.

There are three fixed water levels in the Daxing Branch project. The fixed water levels of the connection between the South Branch project and the Daxing Branch project and the connection between the Langzhuo Branch and the Daxing Branch project are the design water levels, respectively. The fixed water level of the direction of the new airport uses the water level calculated at the other two fixed water levels, the specified operating status of the pump and the specified flow rate of the direction of the new airport.

\section{Pipe Connections}

The boundary conditions for pipe connections (i.e., series, parallel, and branching) should satisfy the continuity Equation (24) and the energy Equation (25), which can be solved in conjunction with the compatibility equations.

$$
\begin{gathered}
\sum_{i=1}^{N} Q_{P, i}=\sum_{j=1}^{M} Q_{P, j} \\
H_{P i}+\frac{Q_{P i}^{2}}{2 g A_{P i}^{2}}-K\left|Q_{P i}\right| Q_{P i}=H_{P j}+\frac{Q_{P j}^{2}}{2 g A_{P j}^{2}}, \quad i=1,2, \ldots, N ; j=1,2, \ldots, M .
\end{gathered}
$$

where $Q_{P, i}, H_{P, i}$, and $A_{P, i}$ are the flow rate, water head, and cross sectional area of the last section of the outlet side pipe, respectively; $Q_{P, j}, H_{P, j}$, and $A_{P, j}$ are that of the last section of the inlet side pipe, respectively; $N$ and $M$ are the number of outlet and inlet side pipes, respectively; and $K$ is the local loss coefficient.

\subsubsection{A Numerical Model of Complex Water Transfer System Based on MOC}

\section{Sectioning for Complex Water Transfer System}

For the complex water transfer system, in dealing with two or more pipes, it is necessary that the time increment $\Delta t$ be taken equal for all pipes. In each pipe, it is required that the number of reaches $N_{j}$ is an integer.

$$
\Delta t=\frac{L_{j}}{a_{j} N_{j}}
$$


It is quickly realized that this relation probably cannot be exactly fulfilled in most systems. In as much as the wave speed is probably not known with great accuracy, it may be permissible to adjust $a_{1}$, $a_{2}, \ldots$, slightly, so that integers $N_{1}, N_{2}, \ldots$, may be found. In equation form this may be expressed:

$$
\Delta t=\frac{L_{j}}{a_{j}\left(1+\varepsilon_{j}\right) N_{j}}
$$

where $L_{j}$ is the length of the $j$-th pipe, $\varepsilon_{j}$ is a permissible variation in the wave speed, always less than some maximum limit of say 0.1 in the study.

2. The Whole Procedure of the Numerical Model of Complex Water Transfer System

A numerical simulation model consisting of modules for steady-state working conditions, transient processes, and the boundary modules for inner nodes of the pipeline, pump, valve, fixed water level, surge chambers, pipe connections, and other components is established, which allow adaptive combination of components and can be globally solved. The calculation steps are shown in Figure 4.

Step 1: Components are combined according to the actual operation of the water transfer system.

Step 2: The operation scheme of the water transfer system and its possible steady-state working conditions are proposed.

Step 3: Pumps, valves, and other components are considered as impedance for the calculation of steady-state working conditions.

Step 4: Analyze the transient processes with the steady-state working condition as the initial working condition.

Step 5: Calculate the parameters, flow rate, and pressure head of each component and inner nodes of the pipeline at time steps before $T>T_{\max }$.

Step 6: Determine the flow rate, pressure head, and extreme value during the transient.

Step 7: Analyze hydraulic responses under different operation schemes, steady-state conditions, and transient conditions.

Step 8: Optimal long-term steady-state operation scheme, coupled operation of pumps and valves, and the optimization of the water transfer project are proposed.

3. The validation of the numerical model of complex water transfer system.

The established numerical model of the complex water transfer system based on MOC has been verified by the experiments and several water-conservancy projects that have been running [23,24], such as Jiaodong water transfer project and Xiangjiaba hydropower station project. 


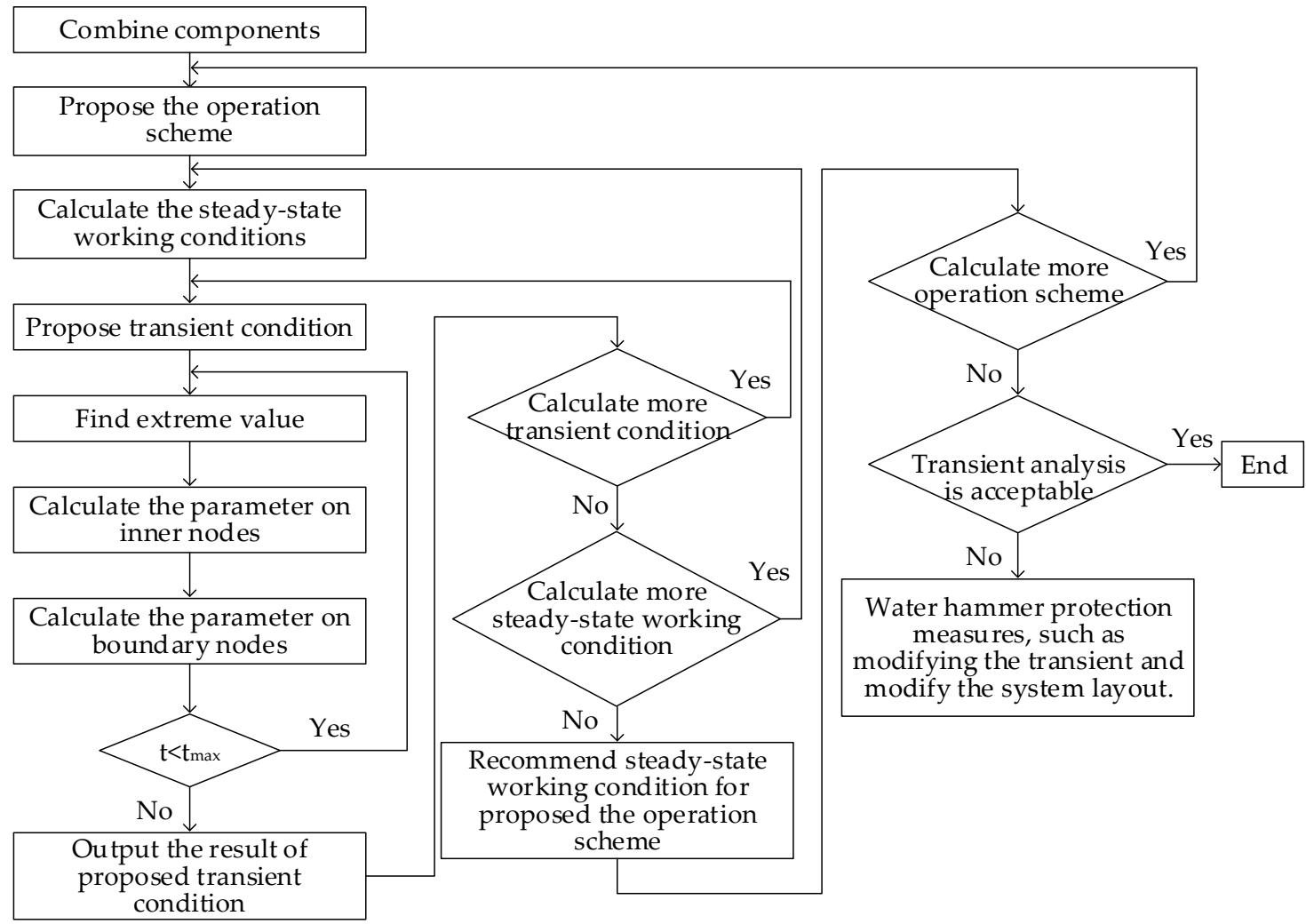

Figure 4. A flow chart for the numerical simulation procedure for complex water transfer systems using the method of characterizations (MOC).

\section{Results and Discussion}

\subsection{Steady-State Analysis}

As the water transfer system is in a steady state most of the time that accounts for the majority of energy consumption, the selection of the steady-state working condition has important implications for cost reduction in the operation of the project. Under the fixed water levels, the steady-state operating schemes of three scenarios for the Daxing Branch project are considered, as shown in Table 3.

Table 3. The steady states of three operating scenarios for the Daxing Branch project.

\begin{tabular}{|c|c|c|c|c|c|c|}
\hline & & \multirow{2}{*}{$\begin{array}{c}\text { OS1 } \\
\text { OS1-C1 }\end{array}$} & \multicolumn{2}{|c|}{ OS2 } & \multicolumn{2}{|c|}{ OS3 } \\
\hline & & & OS2-C1 & OS2-C2 & OS3-C1 & OS3-C2 \\
\hline \multirow{2}{*}{$\begin{array}{l}\text { Calculation } \\
\text { conditions }\end{array}$} & Number of running pumps & 3 & 2 & 2 & 1 & 1 \\
\hline & $\begin{array}{l}\text { The ratio of the running speed } \\
\text { of the pump to the rated speed }\end{array}$ & 1 & 0.9 & 1 & 0.8 & 1 \\
\hline \multirow{8}{*}{$\begin{array}{l}\text { Hydraulic } \\
\text { characteristics of the } \\
\text { steady-state } \\
\text { working condition }\end{array}$} & $\begin{array}{c}\text { The water level of the surge } \\
\text { chamber }(\mathrm{m})\end{array}$ & 53.10 & 52.34 & 52.54 & 51.85 & 52.00 \\
\hline & $\begin{array}{l}\text { The water level of the } \\
\text { regulating tank }(\mathrm{m})\end{array}$ & 32.15 & 32.15 & 29.31 & 30.78 & 29.20 \\
\hline & The flow rate in pipe (2) $\left(\mathrm{m}^{3} / \mathrm{s}\right)$ & 6.33 & 6.33 & 6.95 & 6.68 & 6.94 \\
\hline & The flow rate in pipe (1) $\left(\mathrm{m}^{3} / \mathrm{s}\right)$ & 6.33 & 4.22 & 4.84 & 1.78 & 2.79 \\
\hline & The flow rate in pipe (3) $\left(\mathrm{m}^{3} / \mathrm{s}\right)$ & - & 2.11 & 2.11 & 4.9 & 4.15 \\
\hline & The head of a pump (m) & 39.13 & 30.03 & 36.21 & 24.45 & 31.17 \\
\hline & The flow rate of a pump $\left(\mathrm{m}^{3} / \mathrm{s}\right)$ & 2.11 & 2.11 & 2.42 & 1.78 & 2.79 \\
\hline & The efficiency of a pump & $90.80 \%$ & $91.35 \%$ & $89.42 \%$ & $92.27 \%$ & $86.54 \%$ \\
\hline
\end{tabular}


Table 3 shows the flow rate of each pipe, the number of running pumps, the running speed of pumps, and the flow rate, head and efficiency of a single pump under five schemes of three scenarios. In scenario OS3, when the pump runs at the rated speed, the maximum flow rate in pipe (3) is $4.15 \mathrm{~m}^{3} / \mathrm{s}$ because of the constraints of the minimum operating water level of the regulating tank, which could not satisfy the water demand of the new airport. Therefore, the running speed of the pump should be reduced to reduce the head and flow rate of the pump and increase the water level of the regulating tank. As the running speed of the pump is adjusted to 0.8 of the rated speed, the flow rate in pipe (3) can satisfy the water demand.

When the pump runs at the rated speed under boundary water levels, the flow rate in pipe (1) is reduced in scenarios OS2 and OS3 compared to that in scenario OS1 because of the demand flow rate of pipe (3), resulting in a reduction in the head loss in pipe (1) and the required head of the pump but an increase in the flow rate of a single pump. As a consequence, the efficiency of the pump is decreased in scenarios OS2 and OS3, which may cause a further increase in energy consumption. The increase in the flow rate of each pump results in an increase in the total flow rate demand of pipe (1) and (3), and consequently a decrease in the water level of the regulating tank and an increase in the flow rate of pipe (2).

In scenario OS2, the flow rate demand of pipe (3) can be met whether or not the running speed of the pump is adjusted. The scheme OS2-C2 can increase the amount of water to be transferred. However, as far as energy consumption is concerned, the scheme OS2-C1 is better than OS2-C2. In addition, the steady-state working condition has significant impacts on various transient processes, which should be considered in the selection of steady-state working condition as described in the next Section.

\subsection{Analysis of Transient Processes}

The steady-state working condition is taken as the initial condition for the calculation of the transient process. Therefore, the following transient processes are analyzed with OS1-C1, OS2-C1, OS2-C2, and OS3-C1 as the initial condition when other pipelines are normally operated, respectively.

D1: The valve V7 is closed in a straight line within $400 \mathrm{~s}$.

D2: All pumps fail and valves behind them are also failed to be closed.

D3: All pumps fail and valves behind them are closed to an angle of $72^{\circ}$ within $24 \mathrm{~s}$ and fully closed within $120 \mathrm{~s}$.

D4: Pumps are stopped successively and valves behind them are closed to an angle of $72^{\circ}$ within $24 \mathrm{~s}$ and fully closed within $120 \mathrm{~s}$.

D5: Pumps are started successively and valves behind them are opened in a straight line within $120 \mathrm{~s}$.

D6: The valves V12 and V13 are closed in a straight line within $400 \mathrm{~s}$ under OS2-C1, OS2-C2, and OS3-C1.

Then, the maximum $\left(\mathrm{H}_{\max }\right)$ and minimum $\left(\mathrm{H}_{\min }\right)$ pressure of the system, the maximum reverse speed $\left(\mathrm{N}_{\max \_ \text {rev }}\right)$, and flow rate $\left(v_{\max \_ \text {rev }}\right)$ of the pump, the maximum allowable time interval $\left(\mathrm{T}_{\max }\right)$ with subsequent regulation are shown in Tables $4-7$.

Table 4. The transient processes in three operating scenarios under condition D1.

\begin{tabular}{|c|c|c|c|c|c|}
\hline & & \multirow{2}{*}{$\begin{array}{c}\text { OS1 } \\
\text { OS1-C1 }\end{array}$} & \multicolumn{2}{|c|}{ OS2 } & \multirow{2}{*}{$\begin{array}{c}\text { OS3 } \\
\text { OS3-C1 }\end{array}$} \\
\hline & & & OS2-C1 & OS2-C2 & \\
\hline \multirow{4}{*}{ D1 } & $\mathrm{H}_{\max }(\mathrm{m})$ & 49.129 & 49.131 & 50.844 & 49.993 \\
\hline & $\mathrm{H}_{\min }(\mathrm{m})$ & 2.2858 & 2.488 & 1.986 & 2.438 \\
\hline & $\mathrm{T}_{\max }(\mathrm{s})$ & 2539 & 4604 & 442 & Self-balancing \\
\hline & Subsequent regulation & $\begin{array}{l}\text { Reopen valve V7 or } \\
\text { stop all pumps }\end{array}$ & \multicolumn{3}{|c|}{$\begin{array}{l}\text { Reopen valve V7 or stop all pumps } \\
\text { and close valves V12 and V13 }\end{array}$} \\
\hline
\end{tabular}


Under condition D1, the valve V7 is closed, thus leaving only the regulating tank for water supply to pipe (1) and (3). As a result, the water level of the regulating tank decreases, and then the head of the pump required to transport water to the South Branch increases and the flow rate of pipe (1) decreases. In scenarios OS2 and OS3, the flow rate of pipe (3) also decreases as the water level of the regulating tank decreases.

The flow rate in each pipe and the water level of the regulating tank are shown in Figure 5. It is found that when OS1-C1, OS2-C1, and OS2-C2 are taken as the initial condition, the water level of the regulating tank drops below the lower limit at 2593, 4604, and $442 \mathrm{~s}$, respectively; whereas when OS3-C1 is taken as the initial condition, the water level reaches a new steady state before dropping below the lower limit.

However, measures would be required if the water level does not reach a new steady state, as shown in Table 4. Figure 5b,c shows that when OS2-C2 is taken as the initial condition, there is only $42 \mathrm{~s}$ left after subtracting the valve closing time of V12 and V13 since the water level of the regulating tank is only $0.11 \mathrm{~m}$ higher than the lower limit. When OS2-C1 is taken as the initial condition, the steady-state water level of the new airport is also high due to the high initial steady-state water level of the regulating tank, resulting in a longer time for the drop of water level to the lowest water level, and the flow rate of pipe (3) is reversed at $1512 \mathrm{~s}$, which slows down the decreasing rate of the water level of the regulating tank. As shown in Figure 5d, the flow rate of pipe (3) is reversed at $1855 \mathrm{~s}$ in scenario OS3. Finally, the reverse flow rate of pipe (3) is equal to that of pipe (1) before the water level of the regulating tank reaches the lower limit.
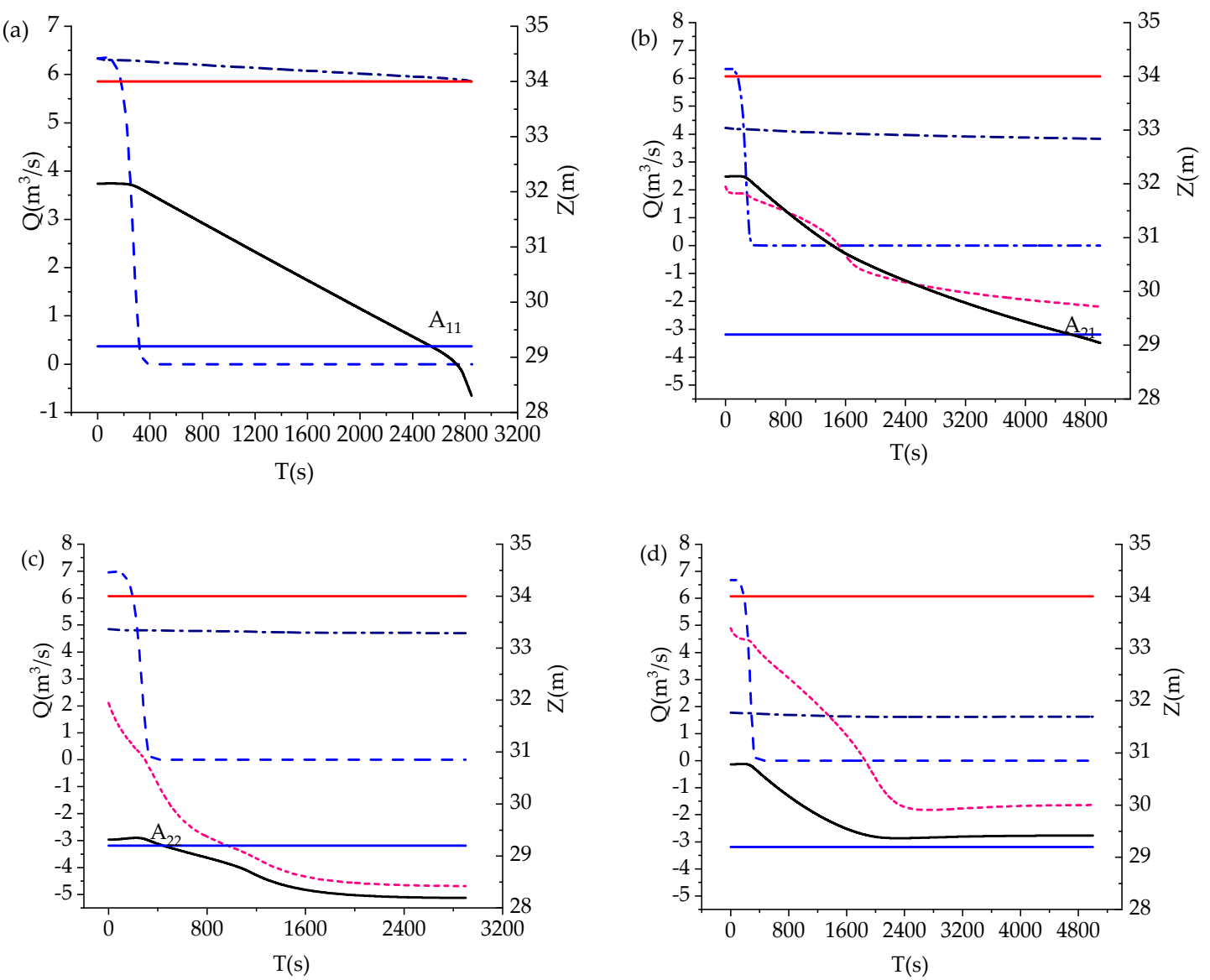

\footnotetext{
--- - The flow rate in pipe (1) - - - The flow rate in pipe (2)-----The flow rate in pipe (3- — The water level of the regulating tank -The lowest operating water level of the regulating tank — The highest operating water level of the regulating tank
}

Figure 5. (a-d) Transient processes of scheme OS1-C1, OS2-C1, OS2-C2, OS3-C1 under condition D1. 
Table 5. The transient processes in three operating scenarios under D2-D4.

\begin{tabular}{|c|c|c|c|c|c|}
\hline & & OS1 & OS2 & & OS3 \\
\hline & & OS1-C1 & OS2-C1 & OS2-C2 & OS3-C1 \\
\hline \multirow{6}{*}{ D2 } & $\mathrm{H}_{\max }(\mathrm{m})$ & 42.698 & 33.604 & 35.973 & 29.829 \\
\hline & $\mathrm{H}_{\min }(\mathrm{m})$ & -5.379 & -2.682 & -5.696 & -0.065 \\
\hline & $\mathrm{N}_{\text {max_rev }}$ & -0.76632 & -0.81 & -0.86546 & -0.91079 \\
\hline & $v_{\text {max_rev }}$ & -0.42729 & -0.45178 & -0.48299 & -0.51744 \\
\hline & $\mathrm{T}_{\max }(\mathrm{s})$ & $1096 \mathrm{~s}$ & $2262 \mathrm{~s}$ & Self-balancing & Self-balancing \\
\hline & Subsequent regulation & Close valve V7 & $\begin{array}{c}\text { Close valves V7, } \\
\text { V12 and V13 }\end{array}$ & & \\
\hline \multirow{6}{*}{ D3 } & $\mathrm{H}_{\max }(\mathrm{m})$ & 42.691 & 48.615 & 48.55 & 45.463 \\
\hline & $\mathrm{H}_{\min }(\mathrm{m})$ & -5.511 & -2.873 & -5.829 & -0.062 \\
\hline & $\mathrm{N}_{\text {max_rev }}$ & 0 & 0 & 0 & -0.07755 \\
\hline & $v_{\text {max_rev }}$ & 0 & 0 & 0 & -0.045 \\
\hline & $\mathrm{T}_{\max }(\mathrm{s})$ & 1278 & $4576 s$ & Self-balancing & Self-balancing \\
\hline & Subsequent regulation & Close valve V7 & $\begin{array}{l}\text { Close valves V7, } \\
\text { V12 and V13 }\end{array}$ & & \\
\hline \multirow{4}{*}{ D4 } & $\mathrm{H}_{\max }(\mathrm{m})$ & 49.496 & 47.09 & 48.444 & 42.741 \\
\hline & $\mathrm{H}_{\min }(\mathrm{m})$ & 0.18 & 0.372 & -0.024 & 0.629 \\
\hline & $\mathrm{T}_{\max }(\mathrm{s})$ & $1439 \mathrm{~s}$ & $4585 \mathrm{~s}$ & Self-balancing & Self-balancing \\
\hline & Subsequent regulation & $\begin{array}{l}\text { Close valve V7 or } \\
\text { restart pumps }\end{array}$ & $\begin{array}{l}\text { Adjust valve V7 or } \\
\text { restart pumps }\end{array}$ & & \\
\hline
\end{tabular}

Under conditions D2-D4, no water would be supplied to the South Branch, and thus the supply of water from the Langzhuo Branch causes an increase in the water level of the regulating tank. It is noteworthy that under condition D2, the failure of pumps and valves behind them results in reverse flow from pumps to the regulating tank and consequently a further increase in the water level of the regulating tank. Therefore, the maximum allowable time interval with subsequent regulation is the shortest. As shown in Table 5, in scenario OS1, the water level of the regulating tank exceeds the upper limit at $1096 \mathrm{~s}$, and the pump is reversed at $143 \mathrm{~s}$. In scenario OS2, when OS2-C2 is taken as the initial condition, the flow rate of pipe (3) increases due to the increase in the water level of the regulating tank. Finally, as the initial steady-state water level of the regulating tank is close to the lower limit, the flow rate of pipe (3) is equal to that of pipe (2) when the water level of the regulating tank is lower than the upper limit. When OS2-C1 is taken as the initial condition, the water level of the regulating tank exceeds the upper limit at $2262 \mathrm{~s}$. In scenario OS3, as the flow rate of pipe (1) is lower than that of pipe (2) and (3), the flow rate of pipe (3) would not be equal to that of pipe (2) before the water level of the regulating tank exceeds the upper limit. The transient processes of scheme OS1-C1, OS2-C1, OS2-C2, OS3-C1 under D2-D4 are shown in Figure 6. 

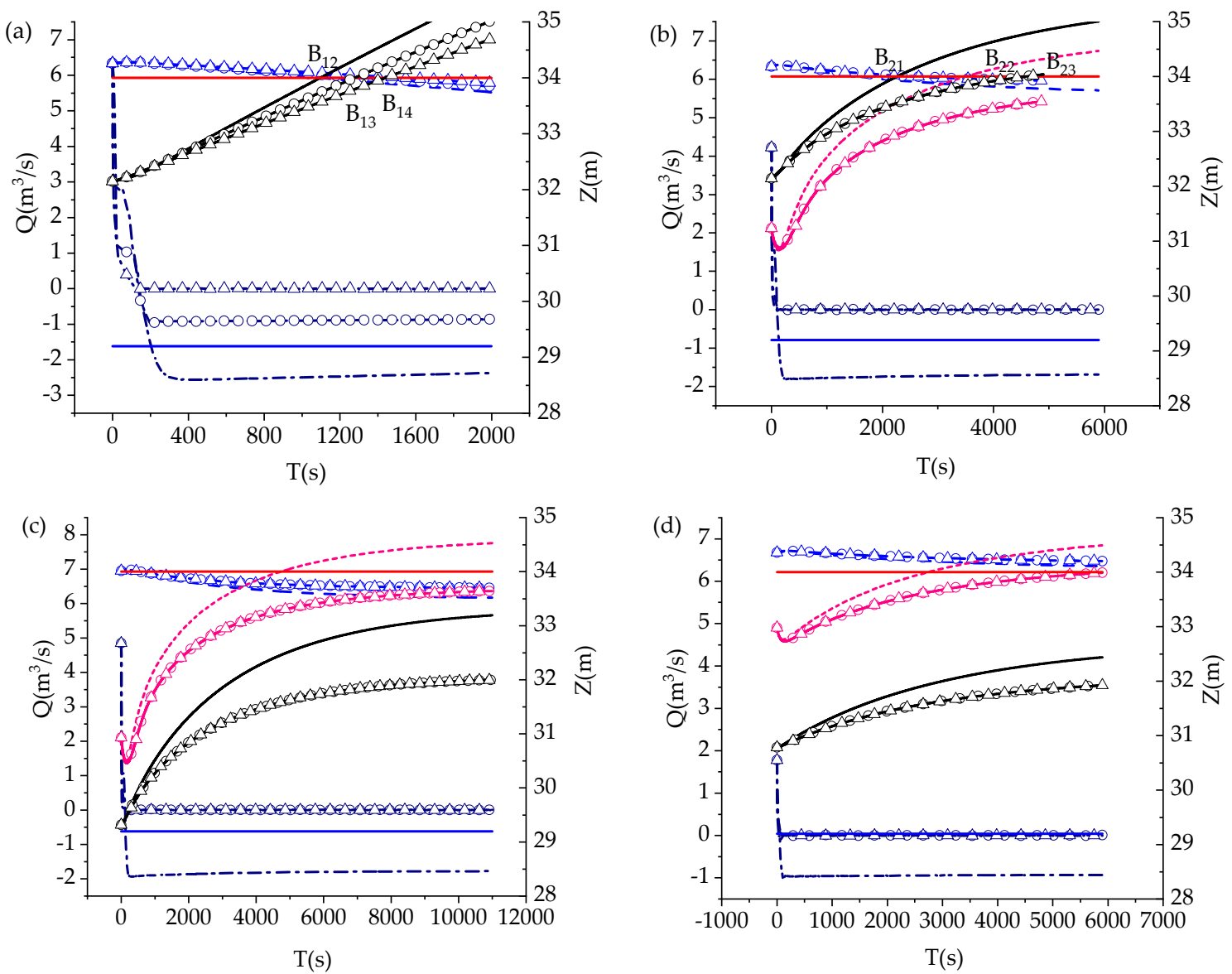

- - - The flow rate in pipe $(1)(\mathrm{D} 2)$

$$
\begin{aligned}
& \text { - } \quad \text { The flow rate in pipe (2)(D2) } \quad \text { - - - - The flow rate in pipe (3)(D2) }
\end{aligned}
$$

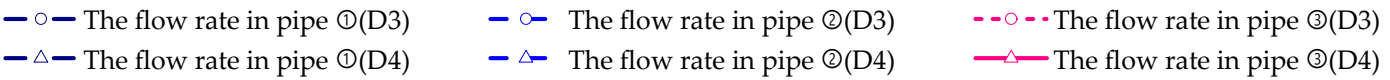

The lowest operating water level of the regulating tank - The highest operating water level of the regulating tank

The water level of the regulating tank(D2) ——The water level of the regulating tank (D3)

$\longrightarrow$ The water level of the regulating tank (D4)

Figure 6. (a-d) Transient processes of scheme OS1-C1, OS2-C1, OS2-C2, OS3-C1 under D2-D4.

Under condition D5, due to the normal startup procedure is to start the pump first and then open the valve behind the pump, thus the flow rate of pipe (1) gradually reaches the required flow rate and the water level of the regulating tank rises slightly before self-balancing.

Table 6. The transient processes in three operating scenarios under D5.

\begin{tabular}{cccccc}
\hline & & OS1 & \multicolumn{2}{c}{ OS2 } & OS3 \\
\hline & & OS1-C1 & OS2-C1 & OS2-C2 & OS3-C1 \\
\hline \multirow{4}{*}{ D5 } & $\mathrm{H}_{\max }(\mathrm{m})$ & 50.715 & 42.241 & 46.914 & 33.495 \\
& $\mathrm{H}_{\min }(\mathrm{m})$ & 5.092 & 5.519 & 2.79 & 3.878 \\
& $\mathrm{~T}_{\max }(\mathrm{s})$ & Self-balancing & Self-balancing & Self-balancing & Self-balancing \\
\hline
\end{tabular}


Table 7. The transient processes in three operating scenarios under D6.

\begin{tabular}{|c|c|c|c|c|}
\hline & & \multicolumn{2}{|c|}{ OS2 } & \multirow{2}{*}{$\begin{array}{c}\text { OS3 } \\
\text { OS3-C1 }\end{array}$} \\
\hline & & OS2-C1 & OS2-C2 & \\
\hline \multirow{4}{*}{ D6 } & $\mathrm{H}_{\max }(\mathrm{m})$ & 34.378 & 37.821 & 27.935 \\
\hline & $\mathrm{H}_{\min }(\mathrm{m})$ & 4.45 & 1.374 & 3.309 \\
\hline & $\mathrm{T}_{\max }(\mathrm{s})$ & $4735 \mathrm{~s}$ & $16003 s$ & $3612 \mathrm{~s}$ \\
\hline & Subsequent regulation & Adjust valve & tart 3\# pump & Adjust valve V7 or start 2\# and 3\# pumps \\
\hline
\end{tabular}

Under condition D6, the closing of valves V12 and V13 results in an increase in the water level of the regulating tank, and subsequently a decrease in the flow rate of pipe (2) and an increase in the flow rate of pipe (1). However, the flow rate of pipe (1) is always lower than that of pipe (2), resulting in a continuous increase in the water level of the regulating tank. Finally, as shown in Table 7, the upper limit is exceeded at 4735, 16003, and $3612 \mathrm{~s}$ when OS2-C1, OS2-C2, and OS2-C3 are taken as the initial conditions, respectively. Additionally, the measures should be taken to ensure the water level of the regulating tank to be lower than the upper limit. In scenario OS2, as the steady-state water level of the regulating tank is lower under condition OS2-C2 than that under condition OS2-C1, the maximum allowable time interval with subsequent regulation is longer when OS2-C2 is taken as the initial condition. The transient processes of scheme OS2-C1, OS2-C2, OS3-C1 under D6 are shown in Figure 7.
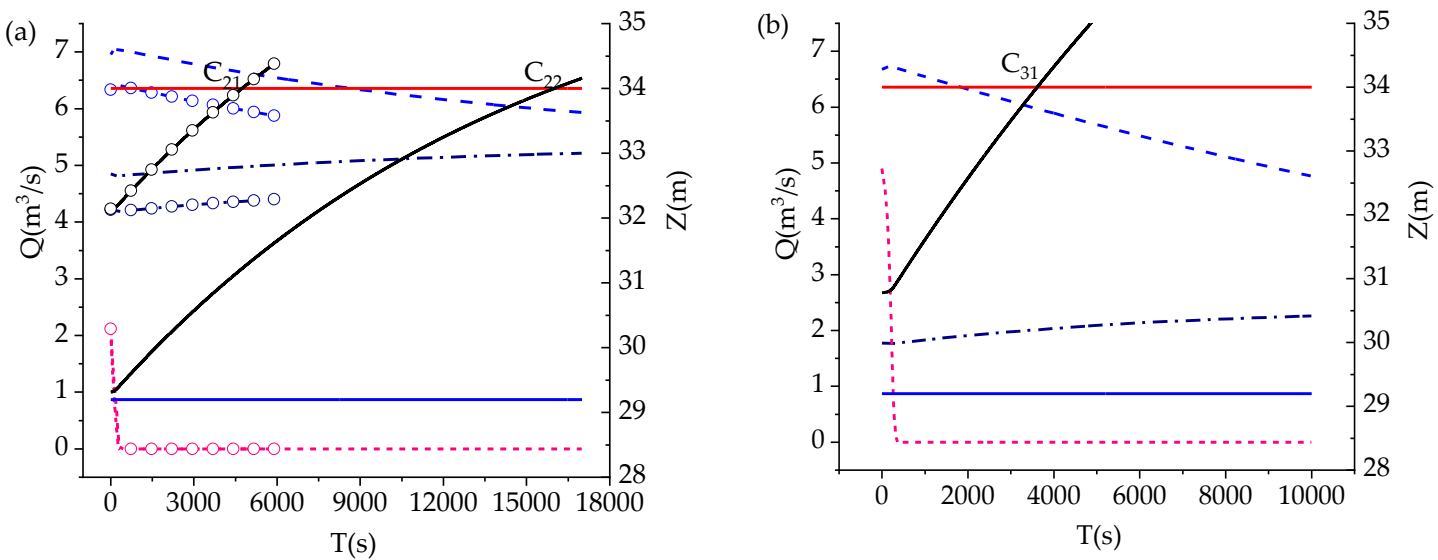

\footnotetext{
- - The flow rate in pipe (1) _ - - The flow rate in pipe (2) . The flow rate in pipe (3)

- - - The flow rate in pipe (1)(OS2-C1) - - - The flow rate in pipe (2)(OS2-C1) - = - . The flow rate in pipe (3)(OS2-C1)

The water level of the regulating tank $\quad-\infty$ The water level of the regulating tank (OS2-C1)

The lowest operating water level of the regulating tank — The highest operating water level of the regulating tank
}

Figure 7. (a,b) Transient processes of scenario OS2 and OS3 under D6.

In summary, OS2-C1 is better than OS2-C2 in terms of the distribution of allowable time interval with subsequent regulation and operation difficulty under different working conditions.

As shown in Tables 4-7, when OS1-C1 is taken as the initial working condition, the maximum pressure is $50.715 \mathrm{~m}$ at the back of 3\# pump under condition D5, because there is no flow as the pump begins to start; while the minimum pressure is $-5.511 \mathrm{~m}$ in front of valve V5 under condition D3, which can be attributed to the long distance between valve V5 and pipe (1). When OS2-C1 and OS2-C2 are taken as the initial working conditions, the pressure reaches a maximum of 49.131 and $50.844 \mathrm{~m}$ in pipe (2) under condition D1 and a minimum of -2.873 and $-5.829 \mathrm{~m}$ at valve V5 under condition D3, respectively. Comparing OS2-C1 with OS2-C2, the peak pressure of the system is smaller because the water rates of pipe (1) and (2) are small as the pump speed decreases. Thus, OS2-C1 is better than OS2-C2 in terms of the peak pressure of the transient. 
Therefore, considering the energy consumption, the amount of water transfer, the peak pressure and the distribution of allowable time interval with subsequent regulation, OS2-C1 is recommended in scenario OS2.

When OS3-C1 is taken as the initial working condition, the pressure of the system reaches a maximum of $49.931 \mathrm{~m}$ in pipe (2) under condition D1, and it reaches a minimum of $-0.065 \mathrm{~m}$ in pipe (1) under condition D2. Due to the higher flow rate of pipe (1) when OS1-C1 is taken as the initial working condition, the maximum pressure is observed at different positions compared to other initial working conditions.

In the hydraulic transient process under the recommended initial conditions, the maximum and minimum pressure envelopes along the pipelines are shown in Figure 8. It is found that the extreme value of pressure in the transient process meets the safety requirements.
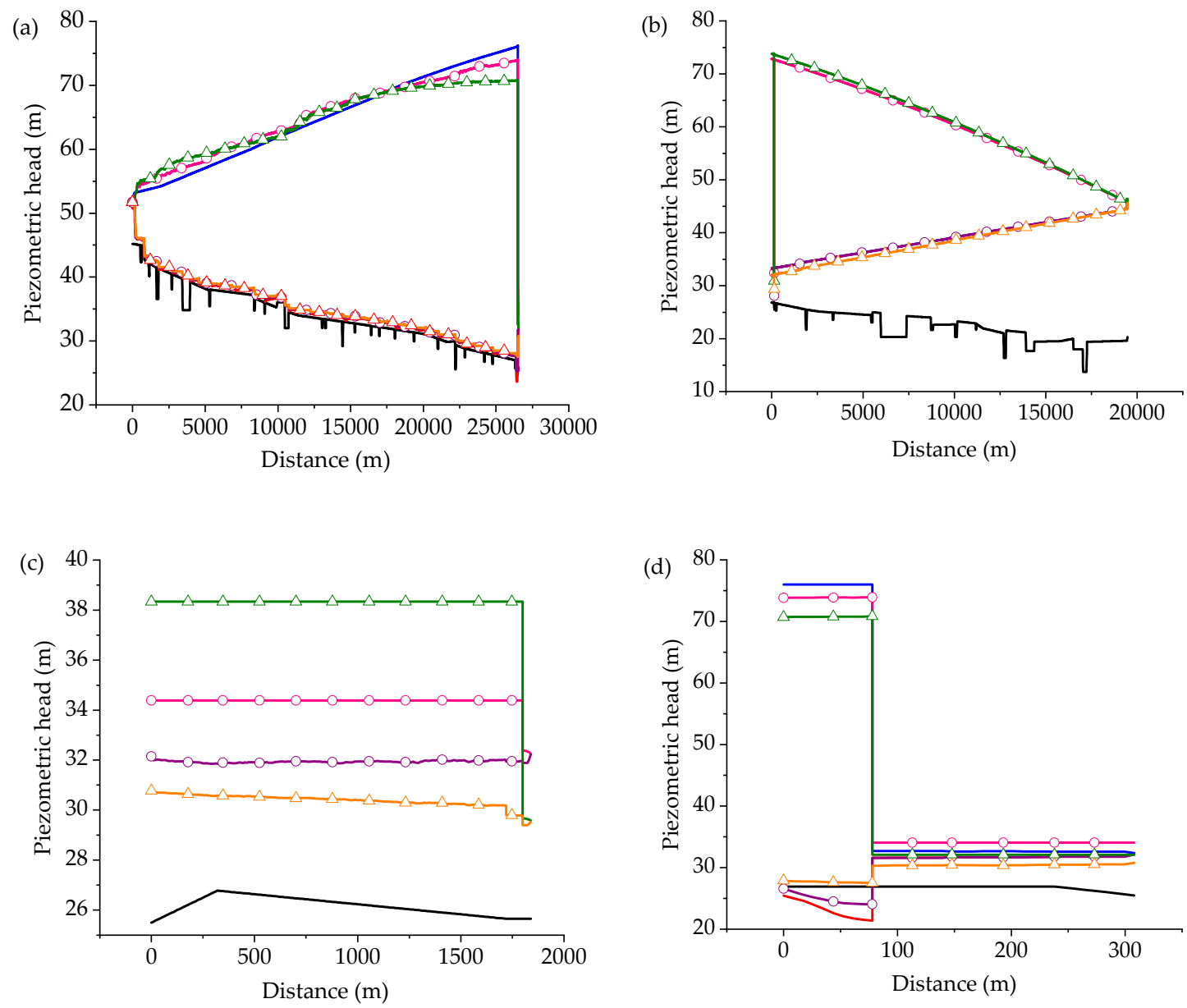

\footnotetext{
The maximum pressure envelope along the pipeline (OS1) — The minimum pressure envelope along the pipeline (OS1)

$\longrightarrow$ - The maximum pressure envelope along the pipeline (OS2) $\longrightarrow$ - The minimum pressure envelope along the pipeline (OS2)

$\neg \_$The maximum pressure envelope along the pipeline (OS3) $\backsim-$ The minimum pressure envelope along the pipeline (OS3)

- The pipe centerline elevation
}

Figure 8. (a-d) The pressure envelopes along pipe (1), (2), (3), and (4).

\subsection{Analysis of Coupled Operation of Pumps and Valves}

A complex water transfer project with multiple water sources and users often requires coupled operation of devices to achieve the switching of working conditions. Although the peak pressures caused by the switching of steady-state working conditions at different periods are lower than that caused by opening/closing valves or pumps or mechanical failure of a device because of small changes 
of the flow rate, the time required to reach the new steady-state working condition ( $\left.\mathrm{T}_{\text {new_steady }}\right)$ and the sequence and the time interval of the coupled operation of pumps and valves have important implications for actual operation.

Taking the switching from scenario OS1 to scenario OS3 as an example. As shown in Table 8, this can be achieved in three steps: $2 \#$ and $3 \#$ pumps are stopped, the speed of $1 \#$ pump is adjusted to 0.8 of the rated speed and opening of valves V10 and V11 in a straight line within $60 \mathrm{~s}$. Since all pumps are in the same pump station, only the sequence of stopping pumps, opening valves, and simultaneous regulation are considered. The time interval between two operations is set to $600 \mathrm{~s}$.

Table 8. The transient processes of the steady-state working conditions for switching from OS1 to OS3.

\begin{tabular}{ccccc}
\hline & & RC13-1 & RC13-2 & RC13-3 \\
\hline & Regulation process & Simultaneous regulation & First, open valves. & First, adjust pumps. \\
Then, adjust pumps. & Then, open valves. \\
OS1-OS3 & $\mathrm{H}_{\max }(\mathrm{m})$ & 42.69 & 42.698 & 42.69 \\
& $\mathrm{H}_{\min }(\mathrm{m})$ & 0.426 & -0.049 & -0.088 \\
& $\mathrm{~T}_{\text {new_steady }}(\mathrm{s})$ & 7736 & 3891 & 10905 \\
& $\mathrm{~T}_{\max }(\mathrm{s})$ & -- & Self-balancing & 2712 \\
\hline
\end{tabular}

The superposed water hammer pressure has negligible effects since pumps and valves to be regulated are located in different pipelines connected via the regulating tank. The water level of the regulating tank varies slightly, as shown in Figure 9a. However, it is difficult to achieve precise synchronization during the regulation, and thus the impact of the regulation sequence is analyzed. The results show that the regulation sequence appears to have no significant effects on the water hammer pressure, but it can substantially affect the water level of the regulating tank. For the control scheme RC13-2, the water level of the regulating tank decreases at first because of the opening of valves V10 and V11 and the increase in the flow rate of pipe (3). As a result, the flow rate of pipe (3) increases at first and then decreases until pumps are stopped, after which it increases again. The water level of the regulating tank increases until the steady-state working condition of scenario OS3 is reached at 3891 s. For the control scheme RC13-3, the water level of the regulating tank increases at first because of the stopping of 2\# and 3\# pumps and the decrease in the flow rate of pipe (1). The water level of the regulating tank increases until the closing of valves V10 and V11 and the flow rate of the pipe (3) increases. The water level of the regulating tank decreases until the steady-state working condition of scenario OS3 is reached at $10905 \mathrm{~s}$.

Given the different trend of the water level of the regulating tank during the transient, it is necessary to analyze the maximum allowable time interval. Table 8 and Figure $9 \mathrm{~b}$ show that if only valves V10 and V11 are opened for the control scenario RC13-2, the water level of the regulating tank would gradually decrease until a new steady-state condition is reached at about $5000 \mathrm{~s}$. However, if only 2\# and 3\# pumps are stopped for the control scheme RC13-3, the water level of the regulating tank would exceed the upper limit at $2712 \mathrm{~s}$. If the speed of $1 \#$ pump is adjusted to 0.8 of the rated speed, the flow rate of pipe (1) will further decrease and thus the water level of the regulating tank will exceed the upper limit more rapidly. For these reasons, the control scheme RC13-2 is recommended in this study. 
(a)

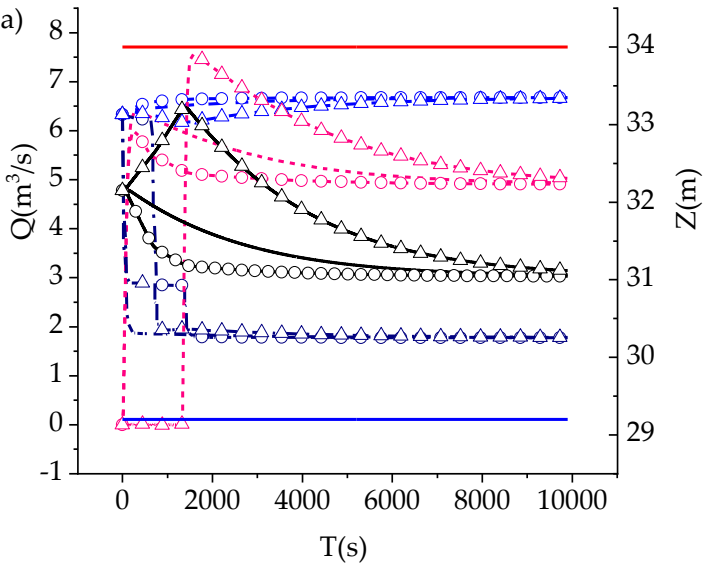

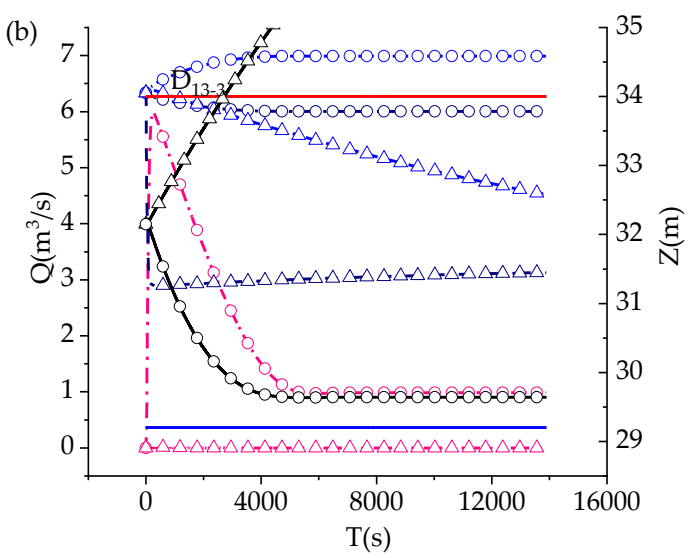

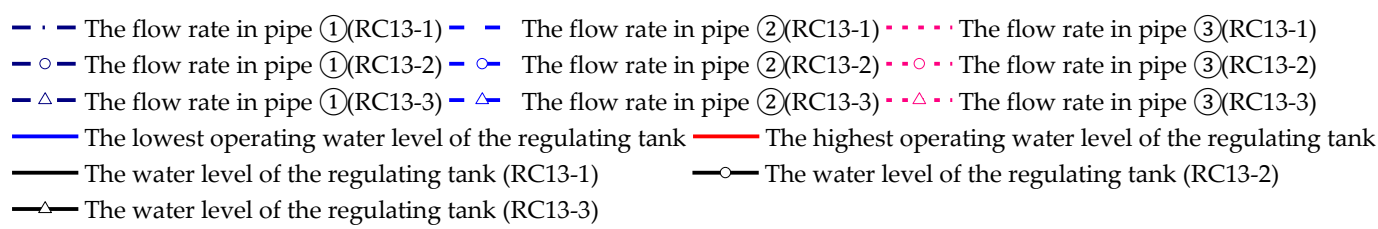

Figure 9. (a) Transient from scenario OS1 to scenario OS3; (b) the maximum allowable time interval between the coupled control of pumps and valves.

\section{Conclusions}

In order to guarantee the operation of the different demands, the design operating ranges of hydraulic structures and hydraulic facilities are wide for multi-demand complicated water transfer systems and switching demand scenario is inevitable. Therefore, in the study, based on the simulation of the Daxing Branch project, the influencing factors of the long-term steady-state operation state are comprehensively analyzed for selecting the appropriate long-term steady-state working conditions of different water demand scenarios, and the coupled operation of hydraulic facilities when switching demand scenario are analyzed for satisfying the changing demand. The numerical simulation model of the Daxing Branch project considering various structures and devices is established using MOC. There are several important conclusions that can be made based on the various simulation results. These conclusions are summarized below.

(1) The steady-state working conditions can have important impacts on the transient process.

(2) Energy consumption and the amount of water transfer, as well as water hammer pressure and the allowable reaction time during the transient process should be taken into account in the selection of long-term steady-state working conditions of different demand scenarios for multi-demand complicated water transfer systems.

(3) The sequence and maximum allowable time interval of the coupled operation of pumps and valves should be considered when switching demand scenario because of the changing demand.

These conclusions can provide some insights into developing practical operation scheduling plan of the Daxing Branch project and other similar complex water transfer projects. However, as Daxing Branch project is still in the construction stage, there is no measured data at present. In the future, when the measured data are accessed, we will further study the real-time adjustment of scheduling plan with measured data.

Author Contributions: Conceptualization, X.L. (Xiaolian Liu), Y.T., X.L. (Xiaohui Lei) methodology, X.L. (Xiaolian Liu) and H.F.; software, X.L. (Xiaolian Liu) and H.F.; formal analysis, X.L. (Xiaolian Liu); resources, Y.T., X.L. (Xiaohui Lei), and H.W.; writing-original draft preparation, X.L. (Xiaolian Liu), writing-review and editing, Y.T. 
Funding: This research was funded by the National Key R\&D Program of China, grant number 2018YFC0406903, and the National Science Foundation of China under Grants, grant number 51609258, 51779268, and 51879273.

Conflicts of Interest: The authors declare no conflict of interest.

\section{References}

1. Afshar, M.H.; Rohani, M. Water hammer simulation by implicit method of characteristic. Int. J. Press. Vessel. Pip. 2008, 85, 851-859. [CrossRef]

2. Chen, T.; Ren, Z.; Xu, C.; Ryan, L. Optimal boundary control for water hammer suppression in fluid transmission pipelines. Comput. Math. Appl. 2015, 69, 275-290. [CrossRef]

3. Schmitt, C.; Pluvinage, G.; Hadj-Taieb, E.; Akid, R. Water pipeline failure due to water hammer effects. Fatigue Fract. Eng. Mater. Struct. 2006, 29, 1075-1082. [CrossRef]

4. Ghidaoui, M.S.; Zhao, M.; McInnis, D.A.; Axworthy, D.H. A review of water hammer theory and practice. Appl. Mech. Rev. 2005, 58, 49-76. [CrossRef]

5. Almeida, A.B.; Koelle, E. Fluid Transients in Pipe Networks; Computational Mechanics Publications: Southampton, UK, 1992.

6. Wan, W.; Zhang, B. Investigation of Water Hammer Protection in Water Supply Pipeline Systems Using an Intelligent Self-Controlled Surge Tank. Energies 2018, 11, 1450. [CrossRef]

7. Wang, C.; Yang, J.D. Water Hammer Simulation Using Explicit-Implicit Coupling Methods. J. Hydraul. Eng. 2015, 141, 04014086. [CrossRef]

8. Wood, D.J. Waterhammer analysis-essential and easy (and efficient). J. Environ. Eng. 2005, 131, $1123-1131$. [CrossRef]

9. Zhao, M.; Ghidaoui, M.S. Godunov-type solutions for water hammer flows. J. Hydraul. Eng. 2004, 130, 341-348. [CrossRef]

10. Bisgaard, C.; SØrensen, H.H.; Spangenberg, S. A finite element method for transient compressible flow in pipelines. Int. J. Numer. Methods Fluids 1987, 7, 291-303. [CrossRef]

11. Kochupillai, J.; Ganesan, N.; Padmanabhan, C. A new finite element formulation based on the velocity of flow for water hammer problems. Int. J. Press. Vessels Pip. 2005, 82, 1-14. [CrossRef]

12. Chaudhry, M.; Hussaini, M. Second-order accurate explicit finite-difference schemes for water hammer analysis. J. Fluids Eng. 1985, 107, 523-529. [CrossRef]

13. Tian, W.X.; Su, G.H.; Wang, G.P.; Qiu, S.Z.; Xiao, Z.J. Numerical simulation and optimization on valve-induced water hammer characteristics for parallel pump feedwater system. Ann. Nucl. Energy 2008, 35, 2280-2287. [CrossRef]

14. Tian, W.X.; Su, G.H.; Wang, G.P.; Qiu, S.Z.; Xiao, Z.J. Mitigating check valve slamming and subsequent water hammer events for PPFS using MOC. Nucl. Sci. Tech. 2009, 20, 118-123.

15. Sibetheros, I.A.; Holley, E.R.; Branski, J.M. Spline interpolations for water hammer analysis. J. Hydraul. Eng. 1991, 117, 1332-1351. [CrossRef]

16. Wan, W.Y.; Huang, W.R. Investigation on complete characteristics and hydraulic transient of centrifugal pump. J. Mech. Sci. Technol. 2011, 25, 2583-2590. [CrossRef]

17. Vakil, A.; Firoozabadi, B. Investigation of Valve-Closing Law on the Maximum Head Rise of a Hydropower Plant. Sci. Iran. Trans. B 2009, 16, 222-228.

18. Kim, S.G.; Lee, K.B.; Kim, K.Y. Water hammer in the pump-rising pipeline system with an air chamber. J. Hydrodyn. 2014, 26, 960-964. [CrossRef]

19. Wan, W.Y.; Li, F.Q. Sensitivity Analysis of operational time differences for a pump-valve system on a water hammer response. J. Press. Vessel. Technol. 2016, 138, 011303. [CrossRef]

20. Wang, X.F.; Ye, H.K.; Tang, R.M.; He, F. Water Hammer in Industrial Pipes, 1st ed.; China Science Publishing: Beijing, China, 1995.

21. Zhu, M.L.; Zhang, X.H.; Zhang, Y.H.; Wang, T. Study on Water Hammer Prevention in Pumping Water Supply Systems by Multi-valves. Int. Conf. Hybrid. Inf. Technol. 2006, 1, 342-346.

22. Zhang, J.; Zhu, X.Q.; Qu, Q.H.; Ma, S.B. Arrangement of air-valve for water hammer protection in long-distance pipelines. J. Hydraul. Eng. 2011, 42, 1025-2032. 
23. Fan, H.G. Study on Transient Flow Calculation of Complex Hydraulic Machinery System. Ph.D. Thesis, Tsinghua University, Beijing, China, 2003.

24. Liu, L.Z. Research on Adaptive Parallel Computation of Transient Simulation and Parameters Optimization. Master's Thesis, Tsinghua University, Beijing, China, 2006.

(C) 2019 by the authors. Licensee MDPI, Basel, Switzerland. This article is an open access article distributed under the terms and conditions of the Creative Commons Attribution (CC BY) license (http://creativecommons.org/licenses/by/4.0/). 